\title{
Phylogenetic relationships between amphimictic and parthenogenetic nematodes of the genus Meloidogyne as inferred from repetitive DNA analysis
}

\author{
PHILIPPE CASTAGNONE-SERENO, CHRISTINE PIOTTE, JAAP UIJTHOF,* PIERRE ABAD, \\ ERIC WAJNBERG, FLAVIE VANLERBERGHE-MASUTTI, MICHEL BONGIOVANNI \& \\ ANTOINE DALMASSO \\ INRA, Laboratoire de Biologie des Invertébrés, BP 2078, 06606 Antibes Cédex, France and *Department of Nematology, \\ Agricultural University, POB 8123, 6700 ES Wageningen, The Netherlands
}

\begin{abstract}
Plant-parasitic nematodes of the genus Meloidogyne are known to reproduce either by crossfertilization (amphimixis), facultative meiotic parthenogenesis or obligatory mitotic parthenogenesis. Among them, $M$. incognita, $M$. arenaria and $M$. javanica are obligatory mitotic parthenogenetic species, while $M$. hapla can reproduce by both cross-fertilization and meiotic parthenogenesis. Phylogenetic relationships in this genus have been investigated by hybridization of BamHI-digested genomic DNAs of 18 geographical isolates belonging to six species with three homologous repeated DNA probes cloned at random from a genomic library of one population of $M$. incognita. Due to the repetitive nature of the probes, the autoradiograms exhibited extensive restriction fragment length polymorphisms (RFLPs) both between and within nematode species. Genetic distance values estimated from hybridization patterns were analysed by two phylogenetic tree-building distance methods, respectively based on constant (UPGMA) and varying (FITCH) rates of nucleotide substitution, and the resulting dendrograms showed a very similar clustering of species and populations. Comparison of these results with the other sources of phylogenetic data available for this genus, i.e. cytogenetic, isoenzymatic and mitochondrial DNA (mtDNA) data, revealed consistency with all but the mtDNA phylogeny. Due to the maternal inheritance of mtDNA, and the parthenogenetic reproductive mode of these organisms, which excludes any possibility of horizontal transfer, we conclude that nuclear DNA phylogeny should represent a more likely evolutionary history of this particular genus, and that interspecific hybridizations between sexual ancestors may account for the results with mtDNA. Thus the early split off of the mitotically parthenogenetic species cluster and $M$. hapla confirms the amphimictic ancestral mode of reproduction of root-knot nematodes. Moreover, the existence of polymorphism within each species at the repeated DNA level is discussed in relation to the adaptative evolution of these parthenogenetic species.
\end{abstract}

Keywords: amphimixis, Meloidogyne spp., parthenogenesis, phylogeny, repetitive DNA.

\section{Introduction}

Nematodes belonging to the genus Meloidogyne, commonly known as root-knot nematodes, constitute the most widely distributed group of plant-parasitic nematodes and a serious damaging pest in many economically important crops, affecting both yield and quality of harvests (Sasser, 1979). Among the 55 described species, four are responsible for at least 90 per cent of the estimated crop losses caused by rootknot nematodes. They are $M$. incognita, $M$. javanica and $M$. arenaria from temperate to tropical regions, and $M$. hapla, largely encountered in cooler climates (Lamberti, 1979).

Early attempts to estimate phylogenetic relationships of root-knot nematodes were based on data from cytogenetical and biochemical studies. The fact that most species of the genus are known to reproduce by facultative meiotic or obligatory mitotic parthenogenesis (Triantaphyllou, 1971), along with a chromosome number varying from 13 to 56 , makes the identification of evolutionary steps more difficult than for sexually 
reproducing (amphimictic) organisms. Nevertheless, it was deduced from cytogenetics that the parthenogenetic species evolved from an amphimictic ancestor, and that several degrees of polyploidy and aneuploidy usually accompanied the modifications observed in the mode of reproduction (Triantaphyllou, 1979; 1985). Electrophoretic analysis of several enzymes led to the same conclusion, with a strong divergence observed between parthenogenetic and amphimictic forms (Dickson et al., 1971; Dalmasso \& Bergé, 1978; Esbenshade \& Triantaphyllou, 1987).

More recently, investigations conducted on mitochondrial DNA (mtDNA) divergence between Meloidogyne species (Powers \& Sandall, 1988) showed a striking discordance with previously published works: on one hand, intraspecific populations were not always clustered together, some populations of the same species being more distantly related to one another than to populations of other species; on the other hand, relations between clusters (i.e. split off order, closeness) showed no consistency with those commonly accepted by nematologists. These quite surprising results need to be compared with other data, in particular at the nuclear DNA level, to elucidate the molecular evolutionary history of this genus.

To provide such information, and because variation in repeated sequences frequently occurs in sibling species (Dowsett \& Young, 1982; Singer, 1982), we cloned at random three homologous repetitive DNA sequences and used them as probes. Phylogenetic relationships in the genus Meloidogyne have been established on the basis of RFLPs deduced from the hybridization patterns of genomic DNAs of 18 populations mainly belonging to the four most damaging species. Moreover, these results were compared with those previously obtained by other means, especially from mtDNA data, in order to provide a more accurate estimation of the phylogeny of root-knot nematodes.

\section{Materials and methods}

\section{Nematode populations}

The names and geographical origins of samples are reported in Table 1. They are derived from the INRA Antibes collection and were identified, at the species level, according to their isoesterase electrophoretic pattern (Dalmasso \& Bergé, 1978), except for 'Pikine' and 'Concarneau', which are not yet described and are presumed to be two new species. This biochemical characterization, routinely used for specific identification purposes in nematology laboratories, was performed on individual females to ensure that no mixture had occurred during nematode multiplication. Except for the $M$. hapla populations 'La Môle' and 'Frontignan', which reproduce by both facultative amphimixis and meiotic parthenogenesis, and perhaps for the undescribed population 'Concarneau' (for which this information is not yet available), all the nematode isolates used in this study belong to mitotic parthenogenetic species.

\section{DNA isolation}

Juveniles of each population were frozen in liquid nitrogen, ground by mortar and pestle and total genomic DNA was extracted from the resulting powder according to a phenol/chloroform procedure (Maniatis et al., 1982). Following ethanol precipitation, DNA was resuspended in $0.01 \mathrm{M}$ Tris $\mathrm{pH} 8$ and $0.001 \mathrm{M}$ EDTA and stored at $-20^{\circ} \mathrm{C}$.

\section{Electrophoresis, Southern blot, labelling and hybridization procedures}

Nematode, bacteriophage and plasmid DNAs were digested using restriction endonucleases purchased from Boehringer Mannheim and used as recommended by the manufacturer. Electrophoresis of digested DNA samples and processing for transfer to nylon membranes were done following standard procedures (Smith \& Summers, 1980). DNAs were radioactively labelled with ${ }^{32} \mathrm{P}$ by nick-translation (Rigby et al., 1977) or by the random oligonucleotide primer method (Feinberg \& Vogelstein, 1983). All hybridizations were conducted overnight at high stringency $\left(6 \times \mathrm{SSC}, 5 \times\right.$ Denhart's, 0.5 per cent SDS at $65^{\circ} \mathrm{C}$ for $16 \mathrm{~h})$. After hybridization, filters were washed at $65^{\circ} \mathrm{C}$ for $2 \mathrm{~h}$ in $2 \times \mathrm{SSC}, 0.1$ per cent SDS and then a further $2 \mathrm{~h}$ in $1 \times \mathrm{SSC}, 0.1$ per cent SDS. After post-hybridization washes filters were exposed to $\mathrm{X}$-ray film with intensifying screen at $-80^{\circ} \mathrm{C}$.

\section{Isolation of repetitive sequences from $\mathrm{M}$. incognita}

A $\lambda$ EMBL3 phage library of the 'Côte d'Ivoire' population of $M$. incognita was prepared as described previously (Castagnone-Sereno et al., 1991) and screened with ${ }^{32}$ P-labelled total DNA of the same isolate by insitu hybridization (Benton \& Davis, 1977). After autoradiography, 40 positive clones were selected at random among those that yielded a strong signal, indicating that they should contain a repeated DNA sequence. To identify potential probes, each bacteriophage DNA was digested to completion with several restriction enzymes, fractionated by 1 per cent agarose gel electrophoresis and transferred onto a nylon filter. After hybridization of the filters with labelled total 
DNA of the 'Côte d'Ivoire' population, three fragments were selected, the intensity of their hybridization signal indicating that they consisted of mid-repetitive DNA. They were as follows: a $1.7 \mathrm{~kb}$ EcoRI/BamHI fragment (clone 4.3), a $0.9 \mathrm{~kb}$ EcoRI/BamHI fragment (clone 13.15) and a $0.8 \mathrm{~kb}$ EcoRI/HindIII fragment (clone 18.10). These fragments were recovered from the gel by electrophoresis through a piece of DEAE paper according to Dretzen et al. (1981).

\section{Subcloning of M. incognita repetitive sequences in pUC18}

The DNAs of the clones $4.3,13.15$ and 18.10 were digested, respectively, with EcoRI/BamHI, EcoRI/ BamHI and EcoRI/HindIII, ligated to pUC18 cleaved with the same set of enzymes and transformed into Escherichia coli strain NM522. Transformants containing plasmids with inserts were selected by plating on ampicillin-containing plates $\left(100 \mu \mathrm{g} \mathrm{ml}^{-1}\right)$ in the presence of Xgal ( $24 \mathrm{mg} \mathrm{ml}^{-1}$ ) and IPTG $\left(25 \mathrm{mg} \mathrm{ml}^{-1}\right.$ ) and selection of white colonies. The inserts of recombinant pUC18 were identified by sizing fragments released upon digestion with the appropriate restriction enzymes.

\section{Analysis of RFLPs data}

The three cloned repetitive sequences were used to probe the digested genomic DNAs of the nematode populations to be tested, in order to assess their relatedness. Autoradiograms were examined for variation in RFLP patterns, only the bands with enough intensity being taken into account for analysis. Similarity coefficients for all pairwise combinations of RFLP groups were calculated using the formula

$F=2 N_{x y} /\left(N_{x}+N_{y}\right)$,

where $N_{x}=$ number of bands in genotype $x, N_{y}=$ number of bands in genotype $y$ and $N_{x y}=$ number of bands shared by genotypes $x$ and $y$ (Nei \& Li, 1979).

$F$ ranged from 0 (no shared bands) to 1 (all bands common to both genotypes). The genetic distance was deduced from $F$ values according to the formula

$d=1-F$.

Dendrograms were generated from the genetic distance data according to two algorithms: the unweighted pair grouping using the arithmetic-averaging (UPGMA) method (Sokal \& Sneath, 1963) performed with SAS software, and the FITCH program in PHYLIP package version 3.2 (Felsenstein, 1988), based on the least square method of Fitch \& Margoliash (1967). The FITCH program from PHYLIP estimates phylogenies from distance-matrix data under the 'additive tree' model according to which the distances are expected to equal the sums of branch lengths between the species. In contrast to UPGMA, it does not assume a constant evolutionary clock. Because no assumption is made on the more ancestral taxon, the tree obtained is unrooted.

\section{Results}

\section{Identification of genomic DNA RFLPS}

Several restriction enzymes that recognize hexanucleotide sequences were used, alone or in combination, to digest the nematode DNAs. All of the enzymes tested produced complete digests and generated a broad size range of DNA fragments after electrophoresis. After transfer of these fragments to nylon membranes and hybridization with the repetitive probes 4.3 , 13.15 and 18.10 , it appeared that the RFLP patterns produced with each enzyme varied in both the number of well-resolved bands useful for further analysis and the resolution of the genomic fragments interacting with the probes (data not shown). As the best and most reproducible results were obtained with $B a m \mathrm{HI}$, this particular endonuclease was selected for the whole experiment.

Because of the high copy number of each cloned sequence in the genome of Meloidogyne spp., and except for the $M$. hapla populations, which exhibited poor signals on the autoradiograms (one or two bands with low intensity), hybridization with the BamHIdigested nematode genomic DNAs was good, with the number of well-resolved bands ranging from 6 to 22 (Table 2). No obvious correlation was detected between chromosome number and the number of hybridizing bands for each of the nematodes tested. On the autoradiograms, the hybridizing area of interest spread from less than $0.5 \mathrm{~kb}$ to about $9 \mathrm{~kb}$, but a strong signal was always observed from unresolved high molecular weight fragments located at the top of the blots. Patterns obtained with each probe showed differences both between species and between populations. Two or more populations were assayed for $M$. incognita, $M$. javanica and $M$. arenaria, and in each case, a set of species-specific bands was observed, while some others displayed extensive differences between geographical isolates of the same species. The hybridization pattern shown in Fig. 1, obtained with probe 13.15 , is a typical example of polymorphisms observed between the isolates examined in this study. 
Table 1 Meloidogyne populations used in this study

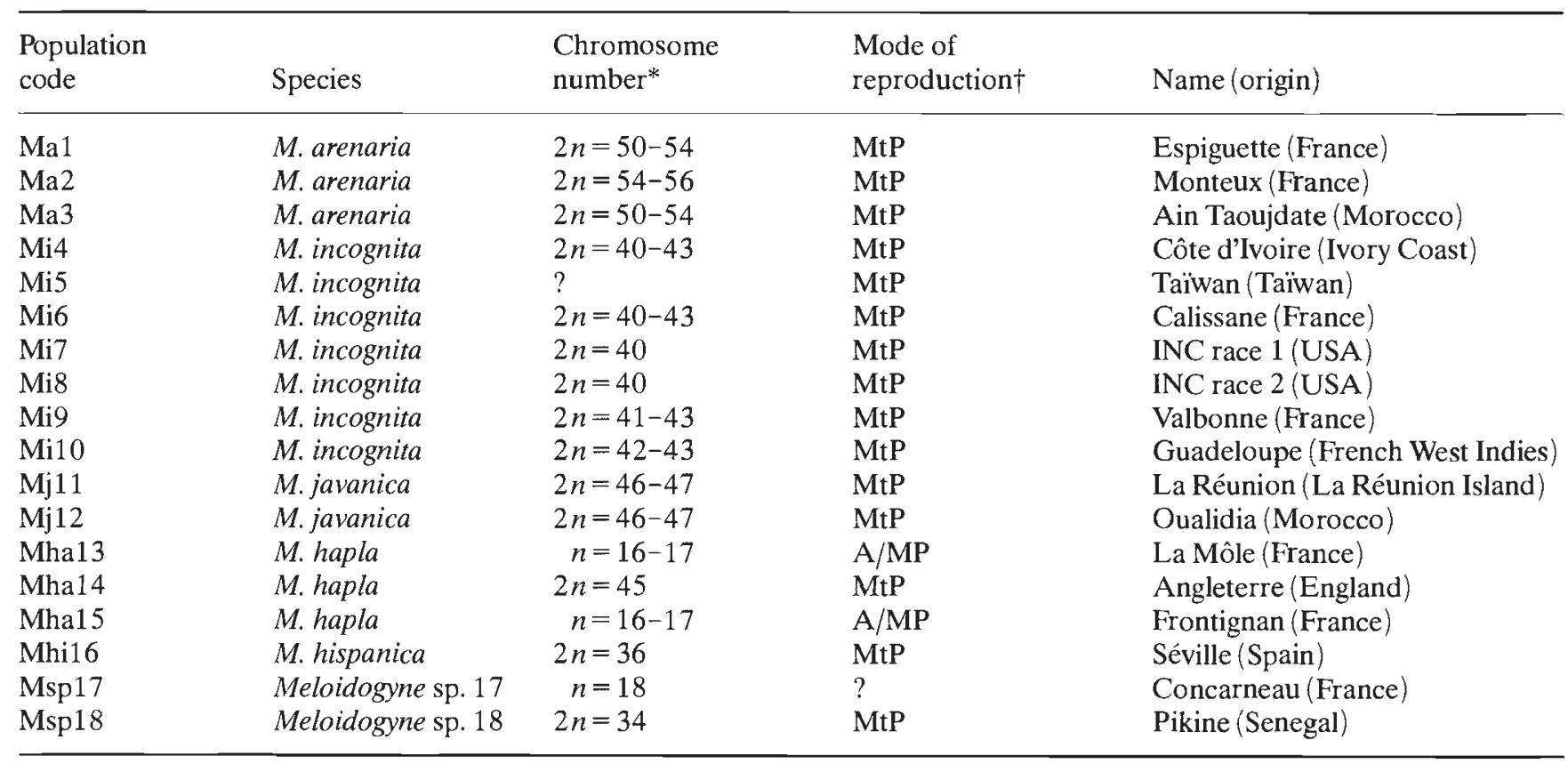

* $2 n$ indicates somatic chromosome number; $n$ indicates haploid chromosome number.

$\dagger \mathrm{MtP}=$ mitotic parthenogenesis; $\mathrm{MP}=$ meiotic parthenogenesis; $\mathrm{A}=$ amphimixis.

\section{Similarity coefficients and cluster analysis}

Similarity coefficients and genetic distances were calculated for each probe and for each pair of populations, the distance dataset being analysed with UPGMA and FITCH programs. All the possible combinations between probes and phyletic methods were assayed, and the six resulting trees displayed the same topology (data not shown). For this reason, two synthetic phylogenetic trees were constructed on the basis of the whole genetic distance between populations, which was weighted by the number of bands of each hybridization pattern according to the following formula:

$d^{\prime}=\left(n_{1} d_{1}+n_{2} d_{2}+n_{3} d_{3}\right) /\left(n_{1}+n_{2}+n_{3}\right)$,

where $n_{i}=$ number of hybridizing bands generated by probe $i$, and $d_{i}=$ distance calculated for probe $i$.

Two synthetic dendrograms were constructed with UPGMA and FITCH programs from the resulting distance matrix (Table 3), which once again shared the same clustering of species and populations, except for the $M$. arenaria 'Espiguette' population (Figs 2 and 3).

Both tree topologies indicated a sharp separation between parthenogenetic and amphimictic species, each group being located at the opposite ends of the dendrograms. Each species for which two populations at least were tested formed a distinct cluster of the trees, with only one exception for the FITCH topology. In that particular case, the 'Espiguette' population appeared to diverge just before the separation between $M$. arenaria and $M$. javanica groups. The Meloidogyne hapla cluster remained independent from all other species on the dendrograms, and the two populations 'La Môle' and 'Frontignan', both reproducing by meiotic parthenogenesis and/or amphimixis were undistinguishable $\left(d^{\prime}=0\right)$. The two remaining undescribed species ('Pikine' and 'Concarneau'), each represented by a single population, were quite distinct from one another and from the major species. Among the obligate parthenogenetic species, $M$. arenaria and $M$. javanica were closer to one another than to $M$. incognita, while $M$. hispanica appeared closer to $M$. incognita than to the two previous ones. Whole genetic distances between conspecific parthenogenetic populations were the lowest in $M$. javanica $\left(d^{\prime}=0.02\right)$, followed by $M$. incognita $\left(0.02 \leq d^{\prime} \leq 0.21\right)$ and $M$. arenaria $\left(0.12 \leq d^{\prime} \leq 0.32\right)$.

\section{Discussion}

It is clear that the species concept for parthenogenetic organisms cannot be based upon the reproductive criterion used for amphimictic forms. But electrophoretic analysis of proteins and isozymes, in correlation with morphology, host ranges and karyotypes have led to the conclusion that the groups described as $M$. 


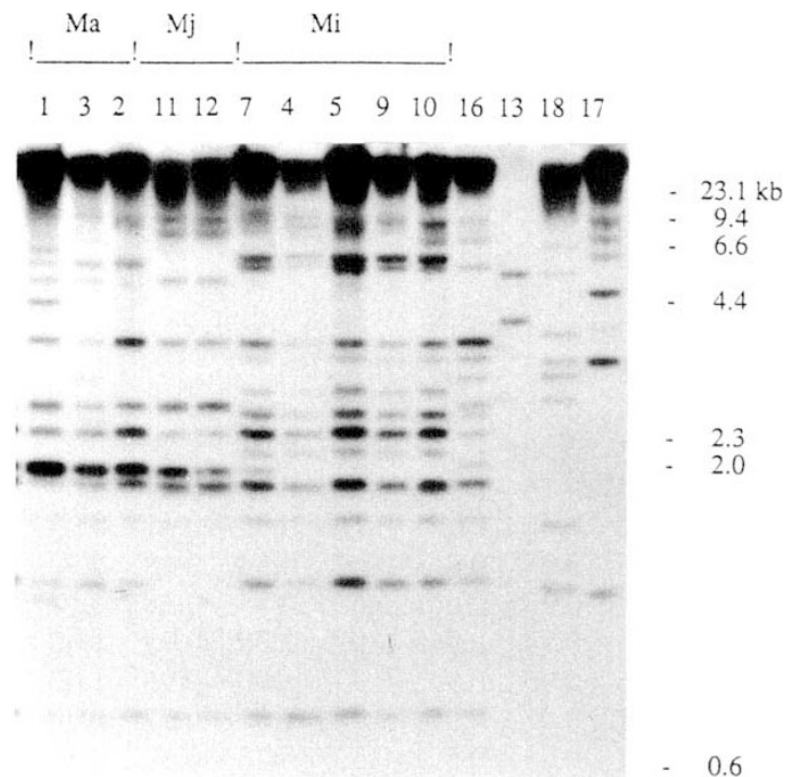

Fig. 1 Autoradiogram of BamHI-digested genomic DNAs of Meloidogyne populations hybridized with probe 13.15. For the population codes, see Table 1.

arenaria, $M$. incognita and $M$. javanica are true species, each of them possessing a unique gene pool (Dalmasso \& Bergé, 1983). RFLPs have been used recently for taxonomic purposes in the genus Meloidogyne (Castagnone-Sereno et al., 1991; Piotte et al., 1992; Powers \& Sandall, 1988; Xue et al., 1992), but assessment of species boundaries among the root-knot nematodes was not the objective of such investigations. Nevertheless, phylogenetic information is available from some of these works, even though it was not their main purpose (Powers \& Sandall, 1988) and the results were fragmentary with respect to the variability of organisms within that particular taxon (Xue et al., 1992). The present study describes evolutionary relationships between populations and species of nematodes of the genus Meloidogyne, and constitutes the first report of such information provided on the basis of genomic repetitive DNA analysis from a large collection of isolates including both parthenogenetic and sexual species.

Our results are consistent with existing phylogenies deduced from isoenzyme surveys (Dickson et al., 1971; Esbenshade \& Triantaphyllou, 1987) but totally disagree with the one proposed by Powers and Sandall (1988), based on genetic divergence observed in mtDNA. The dendrogram that these authors proposed, as reported in Fig. 4, is mainly characterized by the following branching: two major clusters distinguish $M$. arenaria from the other species; $M$. javanica and $M$. incognita populations are easily distinguished on the 
Table 3 Whole genetic distance matrix for the 18 Meloidogyne populations used in this study

\begin{tabular}{rllllllllllllllllll}
\hline & 1 & 2 & 3 & 4 & 5 & 6 & 7 & 8 & 9 & 10 & 11 & 12 & 13 & 14 & 15 & 16 & 17 & 18 \\
\hline 1 & & & & & & & & & & & & & & & & & \\
2 & 0.18 & & & & & & & & & & & & & & & & \\
3 & 0.32 & 0.12 & & & & & & & & & & & & & & & \\
4 & 0.62 & 0.61 & 0.59 & & & & & & & & & & & & & & \\
5 & 0.58 & 0.57 & 0.51 & 0.17 & & & & & & & & & & & & & \\
6 & 0.45 & 0.53 & 0.50 & 0.09 & 0.11 & & & & & & & & & & & & \\
7 & 0.52 & 0.49 & 0.49 & 0.19 & 0.12 & 0.07 & & & & & & & & & & & \\
8 & 0.43 & 0.53 & 0.48 & 0.10 & 0.02 & 0.05 & 0.03 & & & & & & & & & & & \\
9 & 0.55 & 0.55 & 0.55 & 0.16 & 0.07 & 0.14 & 0.09 & 0.09 & & & & & & & & & \\
10 & 0.60 & 0.52 & 0.48 & 0.13 & 0.16 & 0.06 & 0.21 & 0.12 & 0.18 & & & & & & & & \\
11 & 0.27 & 0.26 & 0.25 & 0.66 & 0.62 & 0.54 & 0.58 & 0.52 & 0.65 & 0.54 & & & & & & & \\
12 & 0.29 & 0.31 & 0.23 & 0.66 & 0.65 & 0.58 & 0.58 & 0.57 & 0.67 & 0.58 & 0.02 & & & & & & \\
13 & 1.00 & 0.96 & 0.94 & 0.96 & 0.97 & 1.00 & 0.95 & 1.00 & 0.96 & 0.96 & 1.00 & 1.00 & & & & & \\
14 & 1.00 & 0.96 & 0.95 & 0.95 & 0.97 & 1.00 & 0.96 & 1.00 & 0.96 & 0.96 & 1.00 & 1.00 & 0.33 & & & & \\
15 & 1.00 & 0.97 & 0.97 & 0.97 & 0.98 & 1.00 & 0.97 & 1.00 & 0.97 & 0.97 & 1.00 & 1.00 & 0.00 & 0.33 & & & \\
16 & 0.70 & 0.61 & 0.65 & 0.57 & 0.53 & 0.45 & 0.57 & 0.44 & 0.56 & 0.30 & 0.72 & 0.70 & 0.96 & 0.97 & 0.97 & & \\
17 & 0.91 & 0.82 & 0.87 & 0.65 & 0.66 & 0.72 & 0.75 & 0.67 & 0.66 & 0.65 & 0.67 & 0.76 & 0.95 & 0.97 & 0.97 & 0.72 & \\
18 & 0.76 & 0.77 & 0.78 & 0.82 & 0.84 & 0.87 & 0.73 & 0.86 & 0.82 & 0.80 & 0.78 & 0.83 & 0.89 & 0.88 & 0.88 & 0.87 & 0.84 \\
\hline
\end{tabular}

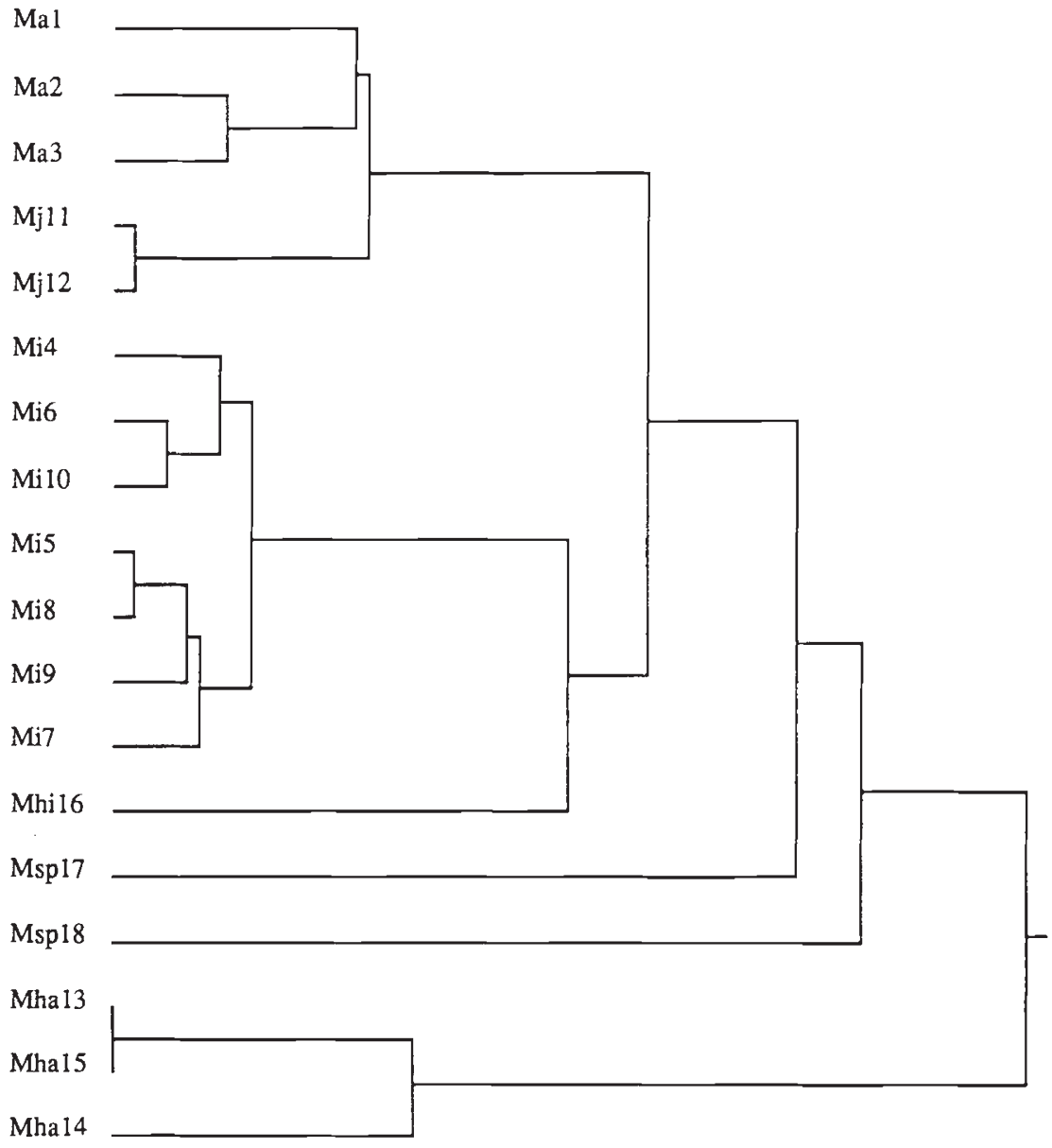

Fig. 2 UPGMA phylogenetic tree for the 18 Meloidogyne populations used in this study, based on distance matrix in Table 3. For the population codes, see Table 1. 


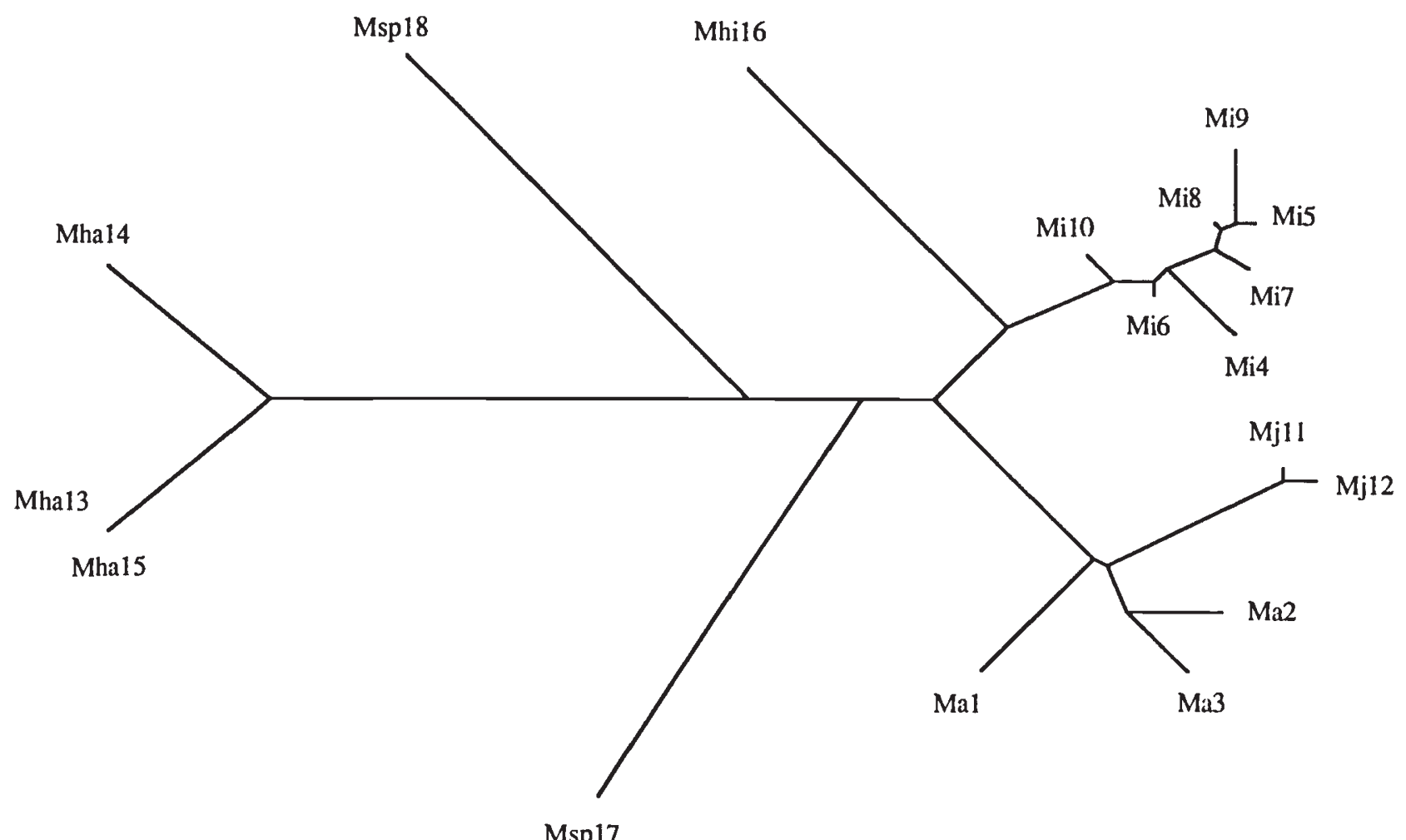

Fig. 3 Phylogenetic tree for the 18 Meloidogyne populations used in this study, inferred from FrTcH analysis performed on distance matrix in Table 3. This topology was chosen among the 536 ones examined by the program. For the population codes, see Table 1.

tree, and occur quite close to one another; M. hapla populations do not form a distinct cluster, one isolate being more closely related to $M$. incognita than to other $M$. hapla. Although we did not work with the same geographical isolates they used, several arguments may be referred to in order to interpret the intraspecific and interspecific branchings in our phenograms. The fact that the $M$. hapla populations 'La Môle' and 'Frontignan' are isolated from all the others is correlated with both their karyotype $(n=16-17)$ and mode of reproduction (meiotic parthenogenesis with facultative amphimixis), which are different from the other species analysed (Dalmasso \& Bergé, 1975). The fact that the 'Angleterre' isolate appears to be quite distinct from the two previous ones, even if these three $M$. hapla populations are evidently clustered together, can be related to the same type of characters $(2 n=45$ and mitotic parthenogenesis). The position of the two undescribed populations 'Pikine' and 'Concarneau' is more difficult to link to any biological feature, as no extensive karyological or reproductive data is available. Preliminary experiments indicate that 'Concarneau' should have a haploid chromosome number close to those of 'La Môle' and

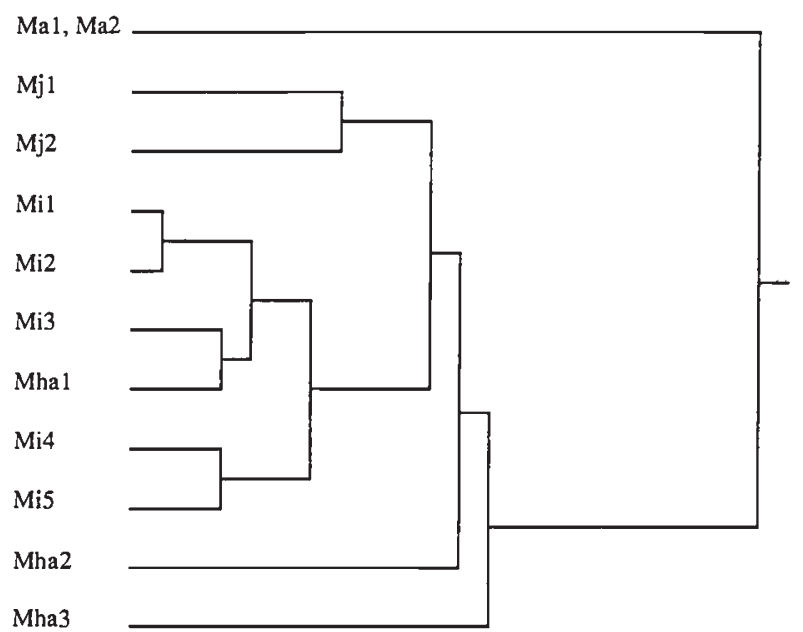

Fig. 4 UPGMA phenogram showing phylogenetic relationships between mitochondrial genomes from 12 Meloidogyne populations (Powers \& Sandall, 1988). As they come from different geographical origins than those tested in our study, only the specific codes (the letters) are the same we used (see Table 1). 
'Frontignan' $(n=18)$, which should imply a sexual reproductive form. However, additional data are needed to confirm their cytogenetical position. The hypothesis that they belong to new species is nevertheless emphasized by their morphometrics (G. Germani, personal communication) and isoesterase patterns (Berthou et al., 1990; Dalmasso \& Bergé, 1983), both of which are different from any known forms. The other ramifications among the mitotic species have already been suggested by isozyme analyses, and are also in agreement with chromosome numbers (Dalmasso \& Bergé, 1978).

As pointed out by Nadler (1990), congruence among independent studies, based on different characters, provides reasonable evidence for a particular phylogenetic estimate. Nevertheless, it is obvious that no single phylogeny is likely to explain all the events from various origins connected with hypothetical relationships between Meloidogyne species and populations. In fact, while the discordance observed here between nuclear and mtDNA has already been reported for several organisms, especially when closely related species have been analysed (Caccone et al., 1988; DeSalle \& Giddings, 1986; Solignac et al., 1986), this is the first time that such a phenomenon has been described in nematodes. The evidence that cytoplasmic gene flow (e.g. mtDNA flow) may occur across species boundaries (Ferris et al., 1983; Powell, 1983) has suggested an explanation for the discrepancy observed between the two sorts of data, mtDNA phylogeny being thus related to interspecific hybridization events. Thus, nuclear DNA phylogeny should better reflect the evolutionary pathway of the genus. This statement is in agreement with the recent study of Mann \& Brandl (1991), who obtained, on several comparative datasets, a better matrix correlation between mtDNA and nuclear distance measures in taxa with well-developed mating behaviour. In our case, the fact that most of the Meloidogyne isolates studied are parthenogenetic does not allow possibility for recent hybridization. Interspecific introgression $(\mathrm{s})$ may have occurred, however, between amphimictic ancestors, and the extinction of one or several ancestral mtDNA haplotypes may account for the mitochondrial phylogeny proposed for these nematodes. Even if the demonstration of ancient hybridization events is presently not possible, analysis of both nuclear and mtDNA of other obligatorily amphimictic (e.g. $M$. carolinensis, $M$. microtyla) and meiotic parthenogenetic species (e.g. $M$. naasi, $M$. exigua) should provide more information on this particular topic. Nevertheless, the early split off of the mitotically parthenogenetic species cluster and $M$. hapla confirms the assumption of Triantaphyllou (1985) on the amphimictic ancestral mode of reproduction of root-knot nematodes, which is a necessary step to confirm our hypothesis.

The phyletic interpretations were performed with classical distance methods, which fit a dendrogram to a matrix of pairwise distances between populations. The phylogeny preferred is the one that minimizes the discrepancy between the expected distance for each pair and the observed one. Even if methods based on genetic distances derived from restriction data are likely to produce erroneous trees, the consistency observed here, with three independent repetitive sequences used as probes, may be preliminary evidence of their efficiency. In addition, considering the wide range of distances involved in our study (i.e. between $M$. hapla and the parthenogenetic species), it can be concluded that our phylogenetic estimations are robust (Tateno et al., 1982; Jin \& Nei, 1991). As the exact evolutionary pathway of these organisms is still unknown, we considered both cases of constant and varying evolutionary rates in the analysis of genetic distance data (UPGMA and FITCH programs, respectively). The algorithm used in the UPGMA method would work perfectly if the data were generated by a clock-like evolution, while the FITCH one does not assume a molecular clock (Felsenstein, 1988). Comparison of the two tree topologies obtained from our data showed that they were largely concordant, apart from the clustering of the $M$. arenaria 'Espiguette' population. The UPGMA topology, with all $M$. arenaria populations clustered together, is in better agreement with previous knowledge, notwithstanding the large isoenzymatic variability found in that particular species (Dalmasso \& Bergé, 1983; Esbenshade \& Triantaphyllou, 1987). Therefore, and whatever the molecular evolution process involved in the Meloidogyne genome, it seems that the molecular clock hypothesis may fit better than that of a varying evolution rate. Such evidence is very weak, however, and sequence data are stongly needed to provide more accurate information on that point.

Intraspecific variation at the enzymatic level in Meloidogyne species is generally very low. This is supported by the fact that enzymes are produced via the expression of genes often highly conserved between closely related taxa, and representing only a minor fraction of the total genome, while non-coding regions are more abundant and submitted to extensive evolutionary changes (McLain et al., 1987). The genomic targets of the probes used in this study are middlerepetitive sequences whose hypothetical functions remain to be determined. Even if no information is available on the structure and organization of these particular regions, the intraspecific polymorphism observed in our study, especially among $M$. arenaria 
and $M$. incognita isolates, may be correlated with their repetitive nature, taking into account their potential variability. As unambiguous identification of these parasites is an essential step for successful management practices, one could imagine that these results might be a starting point for the production of kits for reliable characterization of field populations (Piotte et al., 1992). Such variability within parthenogenetic animal species has already been described, in particular for the brine shrimp Artemia parthenogenetica, in which numerous clonal genotypes occurred within a population despite obligate parthenogenesis (Browne \& Hoopes, 1990). Genotypic variation within asexual lineages of plants has also been documented (e.g. Taraxacum officinale: King \& Schaal, 1990; Richards, 1989). Although no molecular mechanism can now be referred to, mutational events associated with somatic recombination may be involved to explain this phenomenon (Das et al., 1990; Gal et al., 1991). Whatever the precise mechanism, it may subsequently influence the evolution of the genome of Meloidogyne parthenogenetic species, considering their widespread distribution and very large host range.

\section{Acknowledgements}

We thank François Bonhomme for valuable comments on an earlier version of the manuscript and Jacques Gambier and Christian Schlagmulder for their help in photography.

\section{References}

BENTON, w. D. AND DAVIS, R. w. 1977. Screening $\lambda$ gt recombinant clones by hybridization to single plaques in situ. Science, 196, 180-182.

BERTHOU, F., BA-DIALLO, A, DE MAEYER, L. AND DE GUIRAN, G. 1990. Caractérisation chez les nématodes Meloidogyne Goeldi (Tylenchida) de types virulents vis-à-vis du gène Mi de la tomate dans deux zones maraîchères au Sénégal. Agronomie, 9, 877-884.

BROWNE, R. A. AND HOOPES, C. W. 1990. Genotype diversity and selection in asexual brine shrimp (Artemia). Evolution, 44, 1035-1051.

CACCONE, A., AMATo, G. D. AND POWELl, J. R. 1988. Rates and patterns of scnDNA and mtDNA divergence within the Drosophila melanogaster subgroup. Genetics, 118, 671-683.

CASTAGNONE-SERENO, P., PIOTTE, C., ABAD, P., BONGIOVANNI, M. AND DALMASSo, A. 1991. Isolation of a repeated DNA probe showing polymorphism among Meloidogyne incognita populations. J. Nematol., 23, 316-320.

DALMASSO, A. AND BERGE, J. B. 1975. Variabilité génétique chez les Meloidogyne et plus particulièrement chez $M$. hapla. Cah. ORSTOM, sér. Biol., 10, 233-238.
DALMASSO, A. AND BERGE, J. B. 1978. Molecular polymorphism and phylogenetic relationship in some Meloidogyne spp.: Application to the taxonomy of Meloidogyne. J. Nematol., 10, 323-332.

DALMASSO, A. AND BERGE, J. B. 1983. Enzyme polymorphism and the concept of parthenogenetic species, exemplified by Meloidogyne. In: Stone, A. R., Platt, H. M. and Khalil, L. F. (eds) Concepts in Nematode Systematics, Academic Press, London and New York, pp. 187-196.

DAS, O. P., LEVI-MINZI, S., KOURY, M., BENNER, M. AND MESSING, J. 1990. A somatic gene rearrangement contributing to genetic diversity in maize. Proc. Natl. Acad. Sci., U.S.A., 87, 7809-7813.

DESALLE, R. AND GIDDINGS, L. v. 1986. Discordance of nuclear and mitochondrial DNA phylogenies in Hawaiian Drosophila. Proc. Natl. Acad. Sci., U.S.A., 83, 6902-6906.

DICKSON, D. W., HUISINGH, D. AND SASSER, J. N. 1971. Dehydrogenases, acid and alkaline phosphates and esterases for chemotaxonomy of selected Meloidogyne, Ditylenchus, Heterodera and Aphelenchus spp. J. Nematol., 3, 1-16.

DOWSETT, A. P. AND Young, M. W. 1982. Differing level of dispersed repetitive DNA among closely related species of Drosophila. Proc. Natl. Acad. Sci., U.S.A., 79, 45704574.

DRETZEN, G., BELLARD, M., SASSONE-CORSI, P. AND CHAMBON, P. 1981. A reliable method for the recovery of DNA fragments from agarose and acrylamide gels. Anal. Biochem., 112, 295-298.

ESBENSHADE, P. R. AND TRIANTAPHYLLOU, A. C. 1987. Enzymatic relationships and evolution in the genus Meloidogyne (Nematoda: Tylenchida). J. Nematol., 19, 8-18.

FEINBERG, A. P. AND VOGELSTEIN, B. 1983. A technique for radiolabelling DNA restriction endonuclease fragments to high specific activity. Anal. Biochem., 112, 295-298.

FELSENSTEIN, J. 1988. Phylogenies from molecular sequences: inference and reliability. Ann. Rev. Genet., 22, 521-565.

FERRIS, S. D., SAGE, R. D., HUANG, C. M., NIELSEN, J. T., RITTE, U. AND WILSON, A. C. 1983. Flow of mitochondrial DNA across a species boundary. Proc. Natl. Acad. Sci., U.S.A., 80, 2290-2294.

FITCH, W. M. AND MARGOLIASH, E. 1967. Construction of phylogenetic trees. Science, 155, 279-284.

GAL, S,, PISAN, B., HOHN, T., GRIMSLEY, N. AND HOHN, B. 1991. Genomic homologous recombination in planta. EMBO J., 10, 1571-1578.

JIN, L. AND NEI, M. 1991. Relative efficiencies of the maximumparsimony and distance-matrix methods of phylogeny construction for restriction data. Mol. Biol. Evol., 8, 356-365.

KING, L. M. AND SCHAAL, B. A. 1990. Genotypic variation within asexual lineages of Taraxacum officinale. Proc. Natl. Acad. Sci., U.S.A., 87, 998-1002.

LAMBERTI, F. 1979. Economic importance of Meloidogyne ssp. in subtropical and mediterranean climates. In: Lamberti, F. and Taylor, C. E. (eds) Root-knot Nematodes (Meloidogyne species) Systematics, Biology and Control, Academic Press, New York, pp. 341-357.

MACLAIN, D. K., RAI, K. S. AND FRASER, J. M. 1987. Intraspecific and interspecific variation in the sequence and abundance 
of highly repeated DNA among mosquitoes of the Aedes albopictus subgroup. Heredity, 58, 373-381.

MANIATIS, T., FRITSCH, E. AND SAMBROOK, J. 1982. Molecular Cloning: a Laboratory Manual. Cold Spring Harbor Laboratory, Cold Spring Harbor, New York.

MANN, W. AND BRANDL, R. 1991. Nuclear and mitochondrialDNA divergence patterns: are they related to behavior? $Z$. Zool. Syst. Evolut.-forsch., 29, 157-164.

NADLER, S. A. 1990. Molecular approaches to studying helminth population genetics and phylogeny. Int. J. Parasitol., 20, 11-29.

NEI, M. AND LI, W. S. 1979. Mathematical model for studying genetic variation in terms of restriction endonucleases. Proc. Natl. Acad. Sci, U.S.A., 76, 5269-5273.

PIOTTE, C., CASTAGNONE-SERENO, P., UIJTHOF, J., ABAD, P., BONGIOVANNI, M. AND DALMASSO, A. 1992. Molecular characterization of species and populations of Meloidogyne from various geographic origins with repeated-DNA homologous probes. Fundam. Appl. Nematol., 15, 271-276.

POWELL, J. R. 1983. Interspecific cytoplasmic gene flow in the absence of nuclear gene flow: Evidence from Drosophila. Proc. Natl. Acad. Sci, U.S.A., 80, 492-495.

POWERS, T. O. AND SANDALL, L. J. 1988. Estimation of genetic divergence in Meloidogyne mitochondrial DNA. J. Nematol., 20, 505-511.

RICHARDS, A. J. 1989. A comparison of within-plant karyological heterogeneity between agamospermous and sexual Taraxacum (Compositae) as assessed by the nucleolar organiser chromosome. Pl. Syst. Evol., 163, 177-185.

RIGBY, P. W., DIECKMANN, M., RHODES, D. AND BERG, P. 1977. Labelling deoxyribonucleic acid to high specific activity in vitro by nick-translation with DNA polymerase I. J. Mol. Biol., 113, 237-251.

SASSER, J. N. 1979. Pathogenicity, host ranges and variability in Meloidogyne species. In: Lamberti, F. and Taylor, C. E. (eds) Root-knot Nematodes (Meloidogyne species). Systematics, Biology and Control, Academic Press, New York, pp. 257-267.

SINGER, M. F. 1982. Highly repeated sequences in mammalian genomes. Int. Rev. Cytol., 76, 67-112.

SMITH, G. E. AND SUMMERS, M. D. 1980. The bidirectional transfer of DNA and RNA to nitrocellulose or diazobenzylomethyl-paper. Anal. Biochem., 109, 123-129.

SOKAl, R. R. And SNEATH, P. H. A. 1963. Principles of Numerical Taxonomy. W. H. Freeman, San Fransisco.

SOLIGNAC, M., MONNEROT, M. AND MOUNOUlou, J. C. 1986. Mitochondrial DNA evolution in the melanogaster species subgroup of Drosophila. J. Mol. Evol., 23, 31-40.

TATENO, Y., NEI, M. AND TAJIMA, F. 1982. Accuracy of estimated phylogenetic trees from molecular data. I. Distantly related species. J. Mol. Evol., 18, 387-404.

TRIANTAPHYLLOU, A. C. 1971. Genetics and cytology. In: Zuckerman, B. M., Mai, W. F. and Rhode, R. A. (eds) Plant-Parasitic Nematodes, vol 2 Academic Press, New York, pp. 1-34.

TRIANTAPH YLLOU, A. C. 1979. Cytogenetics of root-knot nematodes. In: Lamberti, F. and Taylor, C. E. (eds) Root-knot Nematodes (Meloidogyne species). Systematics, Biology and Control, Academic Press, New York, pp. 85-106.

TRIANTAPHYLLOU, A. C. 1985. Cytogenetics, cytotaxonomy and phylogeny of root-knot nematodes. In: Sasser, J. N. and Carter C. C. (eds) An Advanced Treatise on Meloidogyne, vol 1, North Carolina State University Graphics, Raleigh, pp. 113-126.

XUE, B., BAILlIE, D. L., BECKENBACH, K. AND WEBSTER, J. M. 1992. DNA hybridization probes for studying the affinities of three Meloidogyne populations. Fundam. Appl. Nemtol., 15, 35-41. 